\title{
Uma Abordagem Ecológica à Reforma Administrativa: O Caso Brasileiro
}

JEAN-CLAUDE GARCIA ZAMOR *

Departamento de Govêrno Universidade do Texas em Austin UDC: 35.047 (81)

International Keview of Administrative Sciences - Bruxelles, vol. XXXV, $1969, \mathrm{n} .^{\circ} 4$

Tradução de Sérgio Henrique Abranches

Antes da experiência atual, o Brasil planejou, em três ocasiōes, implantar um programa de reforma administrativa. O primeiro plano consistiu num Projeto de lei de reforma proposto pelo Segundo govêrno de Getúlio Vargas. Ele foi enviado ao Congresso em 1953, mas nunca transformou-se em lei. Em 1956, Juscelino Kubitschek criou uma Comissão para o Estudo de Reformas Administrativas - CEPA - mas ela não chegou a formular realmente um Projeto. A terceira tentativa deu-se em 1963 , durante a presidência de João Goulart, quando foi criado um Ministério da Reforma Administrativa; como nas duas ocasiöes anteriores, a experiência fracassou em fase inicial. Atualmente, uma lei de reforma administrativa - Decreto-lei no 200 - está sendo implementada. Este quarto estôrço parece ter uma chance melhor de Vir a ser realizado e provàvelmente tornar-se-á a primeira reforma administrativa bem sucedida no Brasil.
Êste artigo não será elaborado com base no conteúdo do Decreto-lei n? 200 , nem das leis anteriores, ou da estratégia especifica proposta pela reforma. Em vez disto, seu escopo será o de focalizar todos os fatôres ecológicos, internos e externos, do sistema político, que exercem papel relevante no sucesso ou fracasso de uma reforma administrativa. Isto nos levará a ver a reforma administrativa num contexto mais amplo, como um instrumento para o desenvolvimento total.

Os primeiros projetos brasileiros de reforma foram todos motivados por algumas preocupações básicas comuns, p. e., o desejo de reduzir as despesas governamentais, a necessidade de descentralizar a máquina administrativa $e$, acima de tudo, a urgência de adaptar o velho quadro do serviço público às

* De outubro de 1967 até Julho de 1969, - Dr. Garcia Zamor fol professor visitante na Escola Brasileira de Administração Pública da Fundaçăo Getúlio Vargas, no Rio de Janelro. 
novas obrigações do moderno govêrno. A burocracia brasileira tradicional era estruturada originalmente no sentido de fazer frente apenas a tarefas secundárias, tais como o cálculo de despesas, administração das finanças, transporte e compras, mas não para tratar com problemas de educação, saúde, energia e outros setores cruciais para o desenvolvimento.

Dois fatôres contribuiram para a IImitação das metas dos três primeiros projetos de reforma administrativa. 0 primeiro foi a adoção de objetivos e experiências estrangeiras. Depois da Segunda Guerra Mundial, vários paises que partjciparam do conflito implantaram reformas administrativas para atualizar e descentralizar suas burocracias. Estas experiências tiveram lugar na lugoslávia, Rússia (como prescrito no discurso de Khrushchev de 7 de maio de 1957), Itália, Bélgica (as Comissões Matton e Gérard), Estados Unidos (as duas Comissões Hoover), e outros paises. As reformas giravam em tôrno da descentralização e melhoramento das práticas de pessoal, após êstes paises já haverem alcançado variados, mas substanciais, graus de desenvolvimento. Assim, nestas ocasiőes, a reforma administrativa não era encarada como um instrumento para o desenvolvimento - o necessário para o Brasil e não alcançado, através da adoção de métodos estrangeiros, os quais haviam sido planejados para alcançar objetivos limitados. O segundo fator situa-se no contexto histórico. Antes de 1960, a atenção dos países em desenvolvimento, inclusive - Brasil, não estava voltada para o desenvolvimento como um processo cultural e político. $O$ desenvolvimento econômico era considerado um fenômeno completamente independente que poderia ser alcançado num país seguindo-se certos padröes, tomados de empréstimo, de industrialização. Aumento da produtividade e distribuiçăo do mercado eram as maiores preocupaçōes dêstes paises. Depois que as Nações Unidas designaram os anos de 60 como a "Década do Desenvolvimento", maior atenção foi dada a êste processo nos países em desenvolvimento; e o fato de que o desenvolvimento estava correlacionado com fatôres sociais e políticos, tanto quanto com fatôres econômicos, tornou-se mais largamente reconhecido. Lentamente, os programas de reforma administrativa assumiram a sua nova dimensão de incorporar suas metas ao objetivo mais amplo do planejamento total do desenvolvimento.

O presente programa brasileiro de reforma administrativa fol transformado em lei pelo Presidente Humberto Castello Branco, em 25 de fevereiro de 1967, menos de um mês antes de delxar o govêrno. Pela primeira vez a reforma administrativa foi expressa no contexto de um plano para reformas básicas para o desenvolvimento, que projetava, em complementação à reforma administrativa, a reforma educacional, o desenvolvimento científico e tecnológico e a reforma agrária. Entretanto, foi dada maior atençăo à reforma administrativa que às outras áreas, porque o Govêrno apóia-se pesadamente no seu aparato administrativo para preparar e realizar os outros programas. Um sistema de serviço público obsoleto iria, naturalmente, limitar o escopo do planejamento $\theta$ impedir o desenvolvimento. 
Os cinco princípios básicos da reforma administrativa brasileira são: planejamento, coordenação, descentralização, delegação de competência O contrôle. 1 Dentro dêstes princípios, os objetivos mais importantes são: 1) integrar a execução de várias funções (incluindo programação de orçamento); 2) organizar um quadro de conselheiros para os Ministros de Estado; 3) prover cada Ministério de um mecanismo de contrôle interno que Permitiria a cada Ministro supervisionar efetivamente a administração de seus programas e a aplicação de recursos (despesas especificas).

Um dos novos elementos no processo de descentralização será o fortalecimento do papel de cada Gabinete Ministerial na orientação, coordenação e contrôle das atividades de seu departamento. A lei prescreve a descentralização por três vias, na efetivação das políticas administrativas federais: 1) dentro da estrutura da administração federal; 2) da administração federal para agências estaduais e locais; 3) da administração federal para O setor privado da economia - através de contratos ou concessões. 2

A lei também procura elliminar êstes mecanismos de contrôle cujos custos são maiores que o preço dos riscos envolvidos. No processamento de certos casos, alguns departamentos aplicam métodos rígidos e demorados de contrôle planejados para detectar qualquer irregularidade possivel. A presente lei elimina êste contrôle quando - seu custo - em têrmos de dinheiro O tempo - excede aquêle das irregularidades concebiveis. Nestes casos, é mais econômico absorver o preço de Pequenos erros do que aquêle de um elaborado mecanismo de detecção. Em outros casos, as circunstâncias das quais originavam-se certos procedimentos não mais existem, mas as leis e regulamentos ainda requerem a aplicação de contrôles - uma ilustração da inércia natural do sistema administrativo brasileiro.

Embora possa ser argumentado que a nova lei de reforma não difere muito, em conteúdo, das três outras, ${ }^{3}$ o contexto no qual está sendo formulada é substancialmente diverso. Deve ser feita uma clara distinção entre o tipo e as variaçőes dos regimes políticos anteriores e o presente, quando se considera o conteúdo das diferentes leis e se analisa 0 fracasso das primeiras em trazer reformas. As tentativas, em 1953, 1956 e 1963, de criar um nôvo quadro para o serviço público, ocorreram no contexto de um sistema político relativamente aberto. Por outro lado, o Decreto-lei $n: 200$ está sendo implementado pelos detentores do poder num sistema fechado, cujo caráter autoritário vem aumentando com o correr do tempo.

Uma série de fatôres positivos e negativos favorecem ou impedem o sucesso da aplicação de um plano de reforma. A identificação dêstes fatôres servirá para estabelecer o meio espe-

\footnotetext{
$6.0^{1}$

1 Decreto-lel n. ${ }^{\circ}$ 200. Título II - art.

2 Ibid., capitulo III, art. 6.

3 O professor Kleber Tatinge do Nascimento, da Escola Brasilelra de Administraçáo Pública (EBAP) publicou um interessante artigo "Reflexóes sôbre a Estratégia da Reforma Administrativa: A Experiência Federal Brasileira", no qual êle sustenta a tese de que nos projetos de reforma incluindo o presente, nâo se dispóe de distintas estratéglas, mas o mesmo modêlo estratégico é constantemente renovado. $O$ artigo identifica e define as característícas dêste modêlo estratégico. Ver Revista de Administraçăo Pública (Río de Janeiro: Fundaçáo Getúlio Vargas), 1.0 semestre de 1967, n. $0^{1}$, pp.11-50.
} 
cífico no qual uma reforma administrativa poderia ser posta em prática, e poderia elucidar o complexo processo envolvido na tarefa de mudar a burocracia num país em desenvolvimento. Ainda que algumas das situaçöes apresentadas aqui sejam particulares ao Brasil, outras são características comuns ao resto da América Latina e outras regiões em desenvolvimento. Assim, o reconhecimento e análise dos fatôres ecológicos que poderiam exercer um impacto em qualquer programa de reforma no Brasil, iria também aumentar o entendimento das razöes por que a reforma administrativa nos paises em desenvolvimento poderia ser utilizada como um instrumento para o desenvolvimento total, em lugar de ser utilizada como um instrumento limitado para a mudança da burocracia. As seguintes características pertinentes serão brevemente revistas: crescimento descontrolado do serviço público; baixa remuneração; a fôrça da tradição; educação carente; crescimento das populaçōes urbanas; estrutura social rigida; servidores públicos ociosos; a ação do militar.

\section{CRESCIMENTO \\ DESCONTROLADO DO SERVIÇO PÚBLICO}

De 1947 a 1959, o Serviço Público Federal dobrou, em tamanho, de 150.000 para 300.000 funcionários. $E$ nos dois anos seguintes, outros..... 150.000 foram acrescentados. Em 1962 , o aumento foi de 100.000 , e, em 1963 , de 120.000 , alcançando, nesta época, um total de 676.554 servidores públicos 4 . Muitos dêstes funcionários trabalham meio-expediente, um fato que complicou sèriamente sua supervisão. Em dez chefes de divisão en- trevistados, em 1968, nenhum tinha uma idéia precisa do número de funcionários que estavam diretamente sob seu contrôle ${ }^{5}$. Em certas seçöes, as horas de trabalho não eram computadas. Vários funcionários gastam seu tempo em trabalhos de rotina e nunca adquirem uma visão ampla das metas de seus departamentos. Como resultado, o público não é atendido pròpriamente.

\section{BAIXA REMUNERAÇAOO}

$O$ tremendo incremento no pessoal do Serviço Público Federal não foi acompanhado por um aumento proporcional em treinamento e eficiência. Em lugar de evoluir em espiral ascendente com a inflação, a escala de pagamentos tem permanecido quase estacionária; desde então a contratação de funcionários adicionais foi feita mais ràpidamente que novas dotaçōes pudessem ser introduzidas no orçamento. Sessenta por cento do funcionalismo público recebem menos de quarenta dólares por mês de salário ${ }^{6}$. Assim, o poder aquisitivo do serviço público declinou qualitativamente, especialmente nas mais altas posiçőes da administração federal. Em 1945, os salários mais altos eram de aproximadamente quinze vêzes o mais baixo. Em 1967 , a proporção era de apenas cinco vêzes mais que o menor. O pagamento inadequado era e ainda é uma importante causa do baixo desempenho no trabalho, porque vários funcionários passaram a encarar seus empregos como sinecuras. O tempo é gasto

4 Visẫo Rio de Janeiro, 27 de março de 1968 , p.37.

5 Jornal do Brasil, 7 de Julho de 1963 , p.18. p.18. 
em conversas triviais ou com intermináveis cafèzinhos. 0 moral é relativamente baixo.

Vários servidores bem preparados responderam ao apêlo das emprêsas privadas, que oferecem uma remuneração mais atrativa. Como resultado, as repartiçőes públicas estão superequipadas, a um nivel de amanuenses, com pessoal sem treinamento, enquanto as vagas para pessoal profissionalmente treinado não podem ser preenchidas.

\section{A FÔRÇA DA \\ TRADIÇÃO}

Através dos anos, a fôrça da tradiÇão no Brasil tem sido um vigoroso desafio a todos os programas de reforma administrativa. Isto é manifesto na excessiva centralização da autoridade nos altos escalões da estrutura administrativa e na existência de tantas formas de se ser àrduamente entravado e aprovado por incontáveis funcionários em todo contato com a burocracia. O Presidente tem que pôr sua assinatura em vários processos rotineiros dos diversos Ministérios, um fato que atrasa a ação administrativa - cria excessivo trabalho extra e triVial na periferia do poder, sobrando relativamente pouco tempo para a execução das tarefas principais da Planificação do desenvolvimento 7 . Em outras instâncias, a resistência à mudança vem dessas pessoas que têm interêsses investidos no status quo, seja o esfôrço de um indivíduo em reter seu emprêgo, ou um funcionário supervisor relutante em ceder seu poder $\theta$ prestígio através da redução de sua fôrça de subordinação. Assim, o Problema da supercentralização das decisões $\theta$ o fracasso em delegar auto- ridade estende-se da Presidência aos Ministérios e dêstes para os níveis mais baixos da administração.

A burocracia está, também, infestada com toneladas de documentos desnecessários, que mantêm os funcionários públicos mais atarefados com papel que com pessoas. Quando o atual Ministro do Planejamento autorizou, recentemente, os chefes de divisão a destruir qualquer papel "inútil", fol acolhido com um ruidoso protesto por parte de um distinguido historiador, que preveniu contra a precipitação nessa tarefa, o que poderia vir a ser prejudicial para o estudo da História 8 . Embora a palavra de cautela do historiador mereça ser ouvida, a eliminação de papéis supérfluos é um passo necessário para acelerar a descongestão dos arquivos administrativos e simplificar os processos. No presente, os passos necessários para obtenção de uma carteira de identidade ou mesmo um simples visto de saída, para deixar o País por algumas semanas, constituem uma penosa experiência. 0

7 A excessiva centralização burocrática é uma herança da ditadura e é atribuída ao Govêrno do Presidente Getúlio Vargas, de mentalidade burocrática, que transmitiu a seus sucessores uma volumosa carga de documentos. O Presidente Costa e Silva parece ter uma certa aversăo a êsse tipo de encargo - o que foi um estimulante para os promotores da Reforma Administrativa. Com a aplicaçăo do Decreto-lei n. ${ }^{\circ} 200$, a Presidência libertou-se de $30 \%$ de sua tarefa burocrática, delegando uma parte de suas responsabilidades para os Mínistérios. Como resultado dessa rápida descentralizaçăo, certas repartiçóes do Palácio, que estavam encarregadas de receber e analisar medidas propostas por diferentes agências do Govêrno, antes de serem submetidas ao Presidente, encontraram-se apenas com encargos leves. Entretanto, vários Ministérios que nấo estavam equipados para enfrentar o nôvo fluxo de trabalho estáo encontrando dificuldades.

8 José Honório Rodrigues - "A Reforma Administrativa e a Destruiçăo de Papéis", Jornal do Brasil, 3 de novembro de 1968 , p.33. 
acúmulo de formalidade envolvida é tal que um cidadão deve contratar os serviços de um despachante ${ }^{9}$ para enfrentar a situação. Semelhante aborrecimento é usualmente encontrado no pagamento do Impôsto de Renda. Os representantes do Serviço Nacional de Rendas comportam-se como se estivessem fazendo um favor especial aos pagantes, condescendendo em aceitar o seu dinheiro. Para se tirar uma Carteira de Motorista tem-se que andar muitas milhas através dos corredores burocráticos, e os documentos requeridos pesam várias libras. Êstes e outros sintomas de ineficiência poderiam ser eliminados através do afastamento de inúmeras formalidades desnecessárias.

\section{EDUCAÇĀO CARENTE}

As diferenças básicas entre aplicar uma reforma administrativa num país desenvolvido ou num país como o Brasil, que está em processo de desenvolvimento, repousam em várias áreas, mas a mais importante delas está no nivel de educação e mentalidade dos servidores públicos. Enquanto nos paises mais desenvolvidos um servidor público é, no mínimo, formado no curso secundário, no Brasil $50 \%$ dos funcionários federais não concluíram o curso secundário. Numa pesquisa conduzida por uma revista brasileira, os resultados foram os seguintes: $2 \%$ recusaram-se a declarar seu grau de instrução; $12 \%$ nunca foram à escola; $21 \%$ não terminaram o curso primário; $13 \%$ freqüentaram o ginásio, mas não concluíram o curso; $15 \%$ haviam concluido o ginásio; $13 \%$ freqüentaram a universidade, mas apenas $2 \%$, obtiveram um diploma universitário (bacharelado). 10
Aproximadamente $52 \%$ da população do Brasil são anafabetos. Apenas vinte, em cada mil estudantes brasileiros que entram no curso primário, também entram para as universidades. Ainda pior, todo ano, um número reduzido de universitários formados compete por um número proporcional cada vez menor de posições - a oferta de novos empregos é constantemente ultrapassada pelo aumento crescente de diplomados. Por exemplo, no Brasil existem perto de 17.000 pessoas com grau universitário em Economia, mas apenas 4.000 trabaIham no campo. E cada ano mais 2.000 novos economistas formam-se nas universidades. A atitude brasileira com relação a êsse problema é refletido pelo alto valor cultural e social dado ao bacharelismo, em contraste com 0 prestígio marcadamente baixo concedido à educação industrial. As universidades brasileiras estão em crises profundas, cujas causas são três: primeiro, o fato de que os professôres trabalham apenas meio-expediente e devotam a maior parte de seu tempo e de suas energias a outras atividades; segundo, a negligência intelectual dos estudantes; e terceiro, a não existência de cursos de pós-graduação para - preparo de professôres. Como conseqüência, há carência de uma "mentalidade universitária" real, tanto entre professôres quanto entre estudantes. Um dos ingredientes básicos, no Brasil inexistente, desta mentalidade é o desejo para o diálogo e fé na $\mathrm{co}^{-}$ municação.

9 Um despachante é um protissional que sabe-todos os canais secretos nos 19 birintos da burocracia. Seus serviços têm uma vez que êle poim uma alta demanda, uma voucas horas usoproblema que já fôra considerado

lutamente sem soluçăo.

10 Visão, op. cit., p.40. 
CRESCIMENTO DA

POPULAÇAO URBANA

No Brasil, como na maioria dos paises em desenvolvimento, as tentativas de reforma administrativa falharão se a reforma não é vista como parte de um processo total de desenvolvimento, incluindo desenvolvimento econômico e político e modernização social. O crescimento constante da população urbana no Brasil tem tido um impacto negativo na administração pública. Vários dos "recém-chegados" terminam em favelas 11 cuja vida urbana é caracterizada por abrigos inadequados e falta de serviços comunitários. Sem especialização, êles não podem penetrar no setor industrial. Apenas de oito a dez por cento do potencial humano brasileiro são empregados pela indústria. A fôrça de trabalho fora do setor industrial satura a área limitada do pequeno comércio e da produção artesanal, mas sempre prefere trabalhar na já superequipada administração pública. No seu papel paternalista de provisor social, o Estado freqüentemente emprega funcinonários públicos tão mal preparados. Assim, um passo paralelo à Reforma Administrativa no Brasil deveria ser uma reforma agrária, que poderia reter os agricultores em suas terras. De modo a eliminar as atualmente existentes, mas desnecessárias, funções, o Estado necessita de novos mercados, nos quais esta fôrça de trabalho barata possa ser utilizada. Uma solução seria acelerar a taxa de crescimento econômico, de forma a absorver em suas indústrias a sempre crescente proporção de efetivos humanos. A incapacidade da economia om integrar as novas ondas de migrantes que continuam chegando nos centros urbanos tem como uma de suas conseqüências, mencionada acima, a criação de pressões na administração para absorvê-los. Mais ainda, o desequilibrio social criado por esta situação é agravado pela existência de outro grupo de indivíduos que circula pelas periferias do processo econômico: os recém-formados pelas universidades. Descrevendo essa situação, tão comum nas nações em desenvolvimento, Raul Prebish disse, em têrmos que se enquadram bem na situação brasileira:

"Assim, com a inevitabilidade de uma tragédia grega, a coexistência sociológica de dois elementos altamente explosivos está sendo preparada. Por um lado, o material inflamável representado pela acumulação de uma fôrça de trabalho que não pode ser absorvida em atividades produtivas satisfatórias. De outro, lado, um elemento "detonador" representado pelos dinâmicos, empreendedores, mas frustrados, indivíduos, incapazes de encontrar mercados adequados a suas justificadas ambições. Inelutàvelmente, qualquer acidente de origens internas ou externas que venham a fundir os dois levará a sérias, senão trágicas, conseqüências." 12

\section{A ESTRUTURA SOCIAL RIGIDA}

Do ponto de vista sociológico, a História do Brasil - do descobrimento aos dias atuais - cai em dois períodos distintos: as épocas antes e depois dos anos de Getúlio Vargas. Até

11 Favelas săo residências pobres nos morros e atoleiros que cercam as cidades brasileiras.

12 Raul Prebish - Trade: Sorrow and Concern, in International Development 1966, ed. H. W. Singer et al. (Dobbs Ferry, New York: Oceana Publications, 1967), p.9. 
1930 o Brasil era governado por uma elite de três facções, composta por uma oligarquia de senhores rurais (cujos interêsses eram representados pelos membros do Congresso eleitos pela chapa do velho Partido Social Democrático), a Igreja e a burocracia. A estrutura da elite foi modificada posteriormente $\theta$ inclui, atualmente, apenas dois grupos: os militares e os "economistas-estrategistas" planificadores. 13

Sob a velha elite, uma estrutura social inflexivel impediu a emergência de novos talentos e manteve um sistema de privilégios na distribuição de posições. Mas, lentamente, os burocratas e os detentores de posições eletivas perderam seu poder real e passaram a exercer um papel de "quase-elite". Teòricamente êles eram ainda parte da elite, posteriormente conseguiram algum tipo de autoridade estrutural ou legal, mas êles podiam manter essas posiçōes apenas desempenhando os papéis indicados a êles pelos "detentores do poder." 14

Contudo, a mudança na composição da elite afetou pouco a rígida estrutura social. E ainda hoje um brasileiro pode entrar para o funcionalismo público mais fàcilmente com a ajuda de um "padrinho" 15 que através de altas notas em exames de qualificação.

\section{OCIOSIDADE DOS}

\section{FUNCIONARIOS PÚBLICOS}

Um decreto-lei aprovado em março de 1969 permite que todos os funcionários públicos que percam suas funções por causa da dissolução de suas posições sejam considerados "inativos" com salário proporcional ao tempo de serviço. $O$ decreto-lei fixa sua nova escala de pagamento em $1 / 35$ de seu salário oficial por ano de serviço, $1 / 30$ no caso das mulheres.

Outra lei, aprovada em maio de 1968 , permite a 200.000 funcionários mantendo ofícios desnecessários deixar o funcionalismo público voluntàriamente, em troca do recebimento de $50 \%$ de seus salários, por um período de três anos. Estas duas leis adicionaram novas despesas ao custo da máquina administrativa, que, atualmente, absorve $60 \%$ das dotaçōes do orçamento federal. $16 \mathrm{~A}$ economia que se pretendia alcançar com estas duas leis nunca se materializou; desde então, em vários departamentos novos servidores foram empregados com a saída dos ociosos, um fato que impede a admissão de especialistas necessários, devido a limitações financeiras e falta de espaço para acomodá-los.

\section{A AÇÃO DO MILITAR}

O Decreto-lei no 200 está sendo implementado por um govêrno diferente daquêle que o formulou. Isto é particularmente significante no contexto brasileiro, porque tradicional-

13 A palavra "elite" é usada aqui para eferir aos "detentores do poder" e deve" referir aos "detentores do poder"
ria ser diferenciada da "classe dirigente". Fred Riggs define a classe dirigente entre aquêles membros de uma socíedade en Ele os quais uma elite deve ser recrutada. especifica que membros da classe dirige in podem ser pobres. Ver Administration PrisDeveloping Coutries, The Theory of Miffin, matic Society (Boston: Hougthon

1964), p.125. em entender esta diferenciaçáo $e \mathrm{em}$ ascula de que eram sumir por sua parte o fato de quesionar o "um grupo de elite" capaz de pressiompro sistema político gerou o coup de dezem de 1968.

15 Padrinho - é uma expressáo utilizada para designar o protetor ou patio cinador. cinador.
16 Jornal do Brasil, 20 de outubro
1968 , p.5. 
mente a maioria dos projetos governamentais desapareceram gradualmente com a chegada de novos "detentores do poder". 17 Este estágio atual de continuidade deve-se em parte à ideologia comum dos governos de Castello Branco e Costa e Silva, que criaram juntos a "era revolucionária" na qual o Pais vive atualmente. 18

Outro fator negativo para o desenvolvimento político, mas favorável ao desenvolvimento geral do País, é a transformação dos militares de carreira em uma elite detentora do poder. Embora alguns estudiosos afirmem que o desenvolvimento político e o desenvolvimento sócio-econômico estão positivamente correlacionados, no contexto da América Latina, 19 pode ser mostrado que o Brasil (e possivelmente em outros países latino-americanos) a ascensão dos militares ao poder, rompendo a forma de govêrno constitucional, é tanto um obstáculo ao desenvolvimento político como um estimulante a certas formas de crescimento sócio-econômico. Essa situação deve-se ao papel positivo que os militares têm desempenhado, com relafão ao desenvolvimento geral do País, uma situação que é usualmente reconhecida por todos os segmentos do sistema político, exceto a extrema esquerda.

0 Exército brasileiro reserva aproximadamente $30 \%$ de seu próprio orSamento para projetos de natureza não militar. Além de rodovias e ferrovias, êle oferece trabalhos produtivos a várias corporações. A Aeronáutica está agora construindo os aviōes necessários para a efetiva integração do vasto território nacional. Durante 1968 o primeiro avião de construção inteiramen- te brasileira foi testado com sucesso. Encurtando distâncias com o tráfego aéreo, a Aeronáutica patrocina êste fenômeno tão característico dos mecanismos contrastantes com os quais o Brasil tenta resolver seus problemas: diversas cidades pequenas do interior conhecem o avião antes do carro de boi. As rodovias e ferrovias chegam mais tarde, depois do avião, quando chegam. A Marinha desenvolve a navegação nas áreas fluviais, aumentando assim as comunicações sócio-políticas e pontes econômicas entre as regiões remotas e as partes mais desenvolvidas do País.

A concepção tradicional das Fôrças Armadas, como ilustradas pelas instâncias citadas acima, é vista como um elemento positivo para o desenvolvimento sócio-econômico do Brasil. A questão crucial é como o militar pode abandonar sua participação ativa na política, recobrando, assim, seu pres-

17 Uma exceçăo notável a esta regra é - esfórço contínuo dos sovernos que sucederam o regime de Juscelino Kubitschek em mudar o Govêrno Federal para a nova Capital, Brasília. Vários Ministérios estăo atualmente, tentando coíncidir o comêço da aplícaçấo do Decreto-lei n. $200 \mathrm{com}$ a instalaçăo de suas novas dependências em Brasilia, uma iniciativa muito apropriada e vantajosa.

18 A 28 de agôsto de 1969, posteriormente à redaçăo dêste artigo, Costa e Silva sofreu um derrame e os comandantes militares das três Armas assumiram o Govêrno apesar do preceito constitucional que designava o entáo Vice-Presidente civil como sucessor. No último mês de outubro, essa junta militar escolheu o General-de-Exército Emillio Garrastazu Médici como o nôvo Presidente brasileiro. A Constituiçăo de 1967 sofreu 58 emendas; a maloria delas objetivava a eliminaçăo da participaçáo civil no processo político. A pena de morte para pessoas julgadas de haver cometido atos de subversăo figura, pela primeira vez, na Constituiçấo do Brasil.

19 Para uma discussão recente sôbre êste tópico, ver Martin C. Needler, Political Development and Socioeconomic Development: The Case of Latin America, in The American Political Science Review, setembro, 1968, vol. LXII, n.0 3, pp.889-897. 
tígio e assumindo seu papel tradicional de guardião das instituições democráticas, e, ao mesmo tempo, conservar sua liderança no plano sócioeconômico.

\section{CONCLUSÃO}

Atualmente, o sistema administrativo brasileiro não pode fazer face às demandas do desenvolvimento. A pesquisa dos estudiosos e administradores públicos das causas do fracasso do País em implantar com sucesso a reforma administrativa tem focalizado - conteúdo dos programas de reforma. Isso explica porque suas sugestões geralmente giram em tôrno de matérias tais como treinamento de pessoal e estratégia de reforma (gradualismo, seletivismo, continuidade e motivação/participação). Embora as práticas de pessoal em países em desenvolvimento obstruam freqüentemente a planificação do desenvolvimento, estas práticas são o resultado das influências do meio ecológico da buro. cracia. Assim, tentar corrigi-los, sem identificar êsse meio, seria uma tarefa fútil.

A reforma administrativa também requer prática política e mudanças na mentalidade tanto quanto para um elaborado planejamento da forma e das novas estruturas burocráticas. Por outro lado, a prática política freqüentemente dita um número de passos que contribuem para a modernização da administração pública e provoca algumas reformas que não dependem tanto de teorias. Ainda mais, uma mudança na mentalidade do funcionário público é também uma necessidade urgente, desde que a eficiência da burocracia depende vigorosamente do pessoal que nêle trabalha. Quando um complexo administrativo é defectivo, a interação humana $e$ as atitudes no interior da burocracia têm que ser modificadas. Tal esfôrço será difícil se os fatôres revistos neste artigo năo forem levados em consideração para o caso brasileiro. 